\title{
EM BUSCA DE UMA CULTURA DE ENSINO REFLEXIVO DE PORTUGUÊS PARA ESTRANGEIROS
}

\author{
Dioni Maria dos Santos Paz
}

\section{RESUMO}

Este artigo tem como objetivo repensar sobre as crenças e a cultura de ensinar de professores de línguas, especialmente os de português-língua estrangeira, buscando reflexões para um ensino mais produtivo. Por outro lado, apresentar-se-ão algumas explanações sobre a necessidade de se traçar concepções de ensino de português para estrangeiros, bem como mostrar-se-á a relevância de conhecimentos sobre teorias de aquisição, teorias de aprendizagem e de práticas didáticas e metodológicas que ainda não são conhecidas por esses profissionais.

\section{INTRODUÇÃO}

As pesquisas sobre formação de formadores mostram como cruciais o papel desses formadores em relação aos futuros profissionais. Diversos são os trabalhos que investigam as crenças desses formadores, como também são vários os enfoques dados por pesquisas em relação às crenças dos aprendizes que um dia serão professores.

Este artigo tem como objetivo repensar sobre as crenças e a cultura de ensinar de professores de línguas, especialmente os de português-língua estrangeira, buscando reflexões para um ensino mais produtivo. Por outro lado, apresentar-se-ão algumas explanações sobre a necessidade de se traçar concepções de ensino de português para estrangeiros, bem como mostrar-se-á a relevância de conhecimentos sobre teorias de aquisição, teorias de aprendizagem e de práticas didáticas e metodológicas que ainda não são conhecidas por esses profissionais.

Com essas colocações pretende-se conscientizar os formadores e os professores em formação sobre a necessidade de uma relação formativa entre docentes e discentes do ensino de línguas, a fim de que se possa criar o perfil desses profissionais e solucionar as expectativas de cursos de Letras que venham a oferecer disciplinas que contemplem o português como língua estrangeira ou como segunda língua. Assim, esses futuros profissionais poderão desenvolver um trabalho reflexivo embasado em 
um conjunto de competências lingüísticas e profissionais, sem deixar de lado a imaginação e a criatividade acopladas às crenças e à cultura de ensinar.

\section{A NECESSIDADE DE FORMAÇÃO DE CONCEITOS DE ENSINO DE PORTUGUÊS COMO SEGUNDA LÍNGUA}

Dentro da perspectiva da multiplicidade de sujeitos, saberes, espaços e tempos presentes na formação de formadores, torna-se crucial a análise de novos desafios do ensino-aprendizagem. Em nossa experiência como professora-orientadora de português como segunda língua, vivenciamos que as atividades enriquecedoras para a prática pedagógica são as que envolvem professor e aluno, conjugando participação com criatividade e competência. Essa realidade permite entender melhor a prática do professor e do aluno-professor que, muitas vezes, sem condições de uma formação de conceitos específicos em determinado conteúdo, acham-se motivados em tentar inovar, intuitivamente, com vistas a um ensino produtivo. É o que está acontecendo, na maioria das vezes, com o ensino de português como língua estrangeira, no qual existe uma cultura de ensino baseada na inspiração ou nas crenças dos professores.

D’Andrade (1987) fez um detalhado estudo sobre a modelagem sócio-cultural da mente, no qual ele mostra alguns modelos culturalmente adquiridos de verdades ou crenças, de acordo com modelos de mundo que os usuários manipulam. Um desses modelos é aquele que luta pela superação da falta, da incerteza, quando os profissionais reconhecem que existem as crenças que expressam desejos e sentimentos que estão inseridos na vontade do sujeito. Nessa constatação, a ação expressa uma intenção já cristalizada pela crença, portanto está subjacente à cultura de ensinar.

É com essa convicção que sabemos que os estudos sobre formação de professores de português como língua estrangeira ou segunda língua ainda estão no início e alguns autores como Almeida Filho (1993) e Moita-Lopes (1996) estão tentando delinear o que seria o ensino de português para estrangeiros. Isso nos leva a concluir que o tema ainda não está claramente definido e que mais investigações sobre crenças de professores se fazem necessárias, pois, como os estudos em PLE ainda 
estão no início, os professores de português como língua materna que preparam aulas de português-língua estrangeira estão abandonados com sua cultura de ensino.

O abandono em que se encontram os professores de línguas também foi observado nos estudos feitos por Reynaldi (1999), em sua dissertação de mestrado, na qual ela constatou, através de pesquisa, que esse ensino está sendo realizado em nosso meio de forma intuitiva e não-reflexiva. Segundo a autora, outro aspecto que pode dificultar ao professor ensinar o aluno a aprender, baseado em suas próprias experiências, é que muitas vezes o conhecimento do professor é inconsciente. Ou então os professores já se esqueceram de como aprenderam para poderem fornecer aos alunos um parâmetro que possibilite a busca de alternativas mais condizentes com seus objetivos.

Essas constatações contribuem com reflexões sobre a necessidade de formação de conceitos de ensino de português como segunda língua, a fim de que os cursos de Letras incluam em seus programas disciplinas que contemplem teorias sobre a aquisição da linguagem, particularmente de aquisição de segunda língua, teorias de ensino e teorias cognitivas da aprendizagem, destinadas à formação de professores de línguas, pois acreditamos que é somente através de uma abordagem reflexiva que os profissionais poderão decidir quais das informações são valiosas para atingirem seus objetivos e quais as que se afastam dele.

Fazendo-se um exame sobre o contexto onde profissionais de prática de formação de formadores atuam, observa-se que ocorre uma lacuna ou deficiência em termos de conceitos por esses profissionais. Analisando-se estudos referentes ao ensino de leitura em português para estrangeiros, nota-se que há poucas pesquisas sobre o conhecimento de professores de língua materna sobre conceitos de ensino de leitura em português como língua estrangeira.

Da mesma forma, sabemos que existem muitas culturas referentes ao ensinoaprendizagem de línguas, mas a maioria delas não considera o contexto de ensino e a formação de conceitos de ensino dos professores. Essa realidade leva o professor a reconhecer suas deficiências em adotar certas abordagens devido à sua formação 
profissional, as limitações das teorias conhecidas e do sistema de ensino, frustrandose da sua prática e do seu resultado.

Segundo Kramsch (1987), pode-se inferir uma cultura ordinária e uma cultura cultivada que representam a cultura de grupos sociais elitizados e não-elitizados. Assim, precisaríamos estruturar o nível do saber para o saber-fazer e estabelecer uma interface entre esses conceitos da estruturação da prática e o fazer acadêmico.

Moura, in Oliveira (1999), juntamente com seu grupo de pesquisa da USP, sob orientação de Oliveira, desenvolve uma linha de pesquisa sobre o estudo de conceitos. O Núcleo de Estudos de Conceitos (NEC) faz investigações relativas a esse tema, baseando-se principalmente na concepção teórica sobre conceitos. Para o grupo, "um conceito não é uma entidade isolada identificada por um conjunto de propriedades; para além das propriedades, um conceito também constitui-se das relações com outros conceitos, que formam redes ou teorias, as quais, por sua vez, têm cada conceito como elemento constitutivo." (Oliveira,1999:101)

Partindo de alguns conceitos de ensino-aprendizagem, Nunan (1993) salienta que o papel do professor na sala de aula, conforme as teorias desenvolvidas nos últimos anos, deveria ter deixado de ser central, cedendo seu espaço para o aluno, passando de controlador, para auxiliar e facilitador da aprendizagem, ensinando o aluno a aprender. Porém, como os teóricos não levaram em conta aspectos da formação do professor, características individuais dos professores e alunos que muitas vezes provêm de culturas e formações diversas, essas alterações não ocorreram, uma vez que para o professor poder ajudar o aluno e ensiná-lo a aprender, é necessário que ele entenda como a linguagem funciona e quais processos estão envolvidos na aprendizagem, fatores não explorados durante sua formação.

\section{O ENSINO REFLEXIVO ENTRE PROFESSOR-ALUNO-CONTEXTO}

Quando aprendemos nossa língua materna, não temos conhecimento de outra língua e ainda não adquirimos hábitos de aprendizagem, diferentemente do que acontece com o aprendizado da língua estrangeira. Outra diferença que ocorre quando da aprendizagem da língua materna e língua estrangeira é referente aos contextos onde 
a aprendizagem ocorre, sendo o contato com a língua materna intenso num contexto natural, o que não ocorre com a língua estrangeira.

Cavalcanti e Moita Lopes (1991), Gimenez (1994), Moita Lopes (1996) e Almeida Filho (1995) enfatizam a necessidade de se adotar um ensino reflexivo em sala de aula, melhorando assim a formação do aluno e futuro-professor. Com efeito, é papel dos educadores proporcionarem espaços para a crítica, a reflexão e o diálogo sobre o comprometimento profissional. Nessa perspectiva, teremos um ensino libertador e democrático, que possibilite ao aluno ser sujeito do seu fazer consciente.

Por sua vez, Collins \& Gentner (1987) enfatizam que a analogia de um domínio para outro pode se tornar uma forma cognitivamente poderosa de investigar ou permitir que aconteçam operações e ampliações do conhecimento. Defendem que as analogias permitem que as pessoas adquiram conhecimentos. Então, a organização do conhecimento se dá através de uma ação potencializadora da analogia. É o caráter social e cultural do conhecimento adquirido pelas pessoas, através de suas concepções de abordagem de ensino-aprendizagem.

Discutindo o conceito de abordagem, temos a definição de Almeida Filho (1993). Para ele abordagem equivale a um conjunto de disposições, conhecimentos (que podem incluir as teorias de ensino), crenças, pressupostos e eventualmente princípios sobre o que é linguagem humana, língua materna, e o que é aprender e ensinar língua estrangeira, imprimindo movimento e ação no processo de ensinar. Reconhece que o termo tem sido empregado numa profusão de sentidos por autores distintos, mas que seu objeto direto é o processo ou a construção do aprender e do ensinar uma nova língua. O autor também afirma que a forma de ensinar do professor é determinada por sua abordagem, que varia entre os pólos do explícito/conhecido e do implícito/desconhecido por ele e acrescenta que o professor deve ser capaz de explicitar sua abordagem de ensino, ou seja, seus conhecimentos teóricos (formais e informais) que explicam sua prática.

Ao se referir à abordagem de ensinar, Almeida Filho se reporta também à existência de uma tradição de ensinar, que é resultante da cultura/abordagem de ensinar. Ele afirma que o conjunto de forças das tradições de ensinar, social ou institucionalmente 
marcadas, tem de se integrar de alguma forma com as contribuições pessoais da abordagem do professor .

Ao usar somente o seu conhecimento intuitivo ao ensinar, o professor está usando sua competência implícita, cujas verdades estão mais enraizadas e profundas do que as que orientam o dizer. Porém, a tendência é que a competência implícita se torne cada vez mais explícita. Entretanto, para que isso aconteça, é preciso que o professor questione seu desempenho e se importe com os resultados de seu trabalho. Em outras palavras, o professor tentará explicar o que faz e o porquê faz de determinada forma, aproximando o que faz do que pensa e diz, havendo uma consciência sempre crescente sobre o que faz, procurando não fomentar conflitos entre os valores da sua cultura que estão orientando a sua prática e os contidos na teoria que o professor constrói baseado em uma determinada abordagem que esteja em voga. Embora a conscientização não signifique mudança, ela pode levar a uma mudança se houver persistência, predisposição e oportunidade, sendo, portanto, lenta a ruptura com a prática anterior.

Da mesma forma, Widdowson (1991), ao se referir à abordagem comunicativa, afirma que saber somente como construir orações não viabiliza a comunicação, uma vez que uma sentença pode estar construída corretamente e ter significado como sentença, mas pode ser inadequada como uma resposta em um diálogo. Para ele, entender, falar, ler e escrever orações expressam mais a forma como a linguagem é manifestada do que a forma como acontece em uma situação comunicativa. Assim, certas sentenças, vistas isoladamente, parecem não comunicar uma mensagem, mas elas encontram o seu sentido dentro do contexto a que pertencem, ou seja, o significado não está pronto na língua, ele precisa ser trabalhado, construído e formado a partir de reflexões sócio-culturais e lingüísticas.

Algumas leituras nos mostram que a formação do professor de português como língua estrangeira ou segunda língua é mais deficiente devido à falta de competência lingüístico-comunicativa, o que faz com que essa língua seja ensinada com menos eficácia que as outras disciplinas e tratada com descaso. Porém, enquanto a formação do professor não se alterar, ele não será capaz de preencher as necessidades comunicativas de seus alunos, refletir sobre sua prática e alterar sua abordagem. 
Conforme Gimenez (1994) e Almeida Filho (1995), a formação continuará no exercício da profissão fortalecendo a competência profissional. Esses autores reconhecem a importância de uma formação que conduza a um ensino reflexivo, através do qual o professor investigaria sua prática e não simplesmente seguiria uma rotina de trabalho. Acrescentam que há necessidade de mais pesquisas sobre a forma de pensar do professor e sobre o processo de aprender a ensinar. Para isso, consideram que, primeiro, é necessário investigar qual bagagem o aluno traz consigo quando ingressa no curso de Letras e que os alunos e professores devem ser encorajados a refletirem não só sobre a prática atual, mas também sobre sua origem para descobrir de onde ela vem e o que faz com que seja da forma que é. Somente através dessa investigação é que será possível a reformulação de conceitos dos professores, uma vez que, refletindo sobre suas experiências passadas, eles poderão descobrir a origem de seus conhecimentos sobre o ensino/aprendizagem e as relacionar com suas experiências, tornando possível a reformulação.

Moita Lopes (1996), por outro lado, enfoca a importância da linguagem no processo educacional, afirmando que a compreensão de sua natureza é essencial na formação de qualquer professor. Investigando salas de aula, ele reconhece semelhanças entre as aulas de língua materna e língua estrangeira. Através de pesquisas já realizadas, notou que o mesmo ocorre com relação às aulas das outras disciplinas. Essas semelhanças são justificadas, principalmente, pelo fato do ensino ser centrado no professor que interage com seus alunos, fato não relevado nos programas de formação de professores, estando o foco mais no conteúdo e não na metodologia. Porém, a metodologia de ensino de qualquer disciplina envolve principalmente a linguagem em uso, ou seja, o discurso e a interação. O autor cita três pontos que deveriam ser incluídos em programas de formação de professores para que eles sejam conscientizados sobre a importância da linguagem nos processos educacionais de qualquer nível: a centralidade da leitura na escola, o papel da interação na aprendizagem, a construção social do significado.

Abordando a centralidade da leitura na escola, Moita Lopes afirma que a educação de todo professor deve levar à compreensão dos processos de leitura, ou seja, deve ser levado a reconhecer que os significados são construídos socialmente, de acordo com 
os valores políticos, históricos e culturais do momento que se está vivendo, que pode ser diferente daquele que o professor prestigia e que acredita que o aluno deve apreender para ser bem-sucedido.

Sobre a interação, Moita Lopes declara que se é através dela que a aprendizagem e o conhecimento são construídos, justifica-se a inclusão de estudos que levem à compreensão desse processo, que é mediado pela linguagem, nos cursos de formação de professores. Com relação à construção social do significado, ele ocorre na relação entre as pessoas que, quando falam, o fazem de algum lugar social específico, baseadas em suas culturas, sendo esse significado afetado pela subjetividade de quem profere o discurso. Desse modo, ao não aceitar as sugestões e opiniões dos alunos, o professor exclui sua participação da construção social do significado. Para o autor, o processo de formação de qualquer professor deve incluir, pelo menos, um componente central que focalize a interação e um outro que dê meios para o professor refletir e investigar sua prática.

Também se referindo à interação e ao processo de reflexão na aprendizagem de uma língua estrangeira, Krashen (1982) considera que a aquisição é responsável pela fluência e é inconsciente, ou seja, os aprendizes só se conscientizam do que são capazes quando se percebem comunicando na nova língua, assemelhando-se à aquisição da língua materna. A aprendizagem, por outro lado, que tem a função de monitor, refere-se à conscientização das regras da língua, que segue uma ordem natural e previsível de aprendizagem, dependendo do grau de dificuldade. Contudo, só as usamos conscientemente quando há tempo para fazê-lo, quando estamos focalizando a forma, não o sentido, e quando sabemos a regra.

Portanto, não resta dúvida de que as crenças exercem influências sobre a prática e a cultura de ensinar, uma vez que a consciência dos desejos, tanto por parte dos professores quanto dos alunos em formação, conduz a uma intenção transformada em ação. Ação essa que será intuitiva ou reflexiva de acordo com o contexto educacional onde estão emquadrados esses futuros profissionais.

\section{CONCLUSÃO}


Com as colocações acima, procurou-se ressaltar a importância de se conscientizar formadores e futuros professores de línguas, especialmente professores de português-língua estrangeira, sobre a cultura de ensinar e as crenças em relação ao papel do professor no ensino-aprendizagem de línguas. Da mesma forma, procurouse mostrar que, ao refletir sobre determinados conceitos já estabelecidos, esses professores podem ter consciência sobre suas atitudes em relação ao ensino e à formação profissional.

Desse modo, a relevância de se estabelecer novos perfis de formadores e de professores em formação reside no fato de que o conhecimento sobre teorias de aquisição e teorias de aprendizagem, além de lingüística aplicada e pragmática, devem constituir subsídios para as práticas pedagógicas desses profissionais. Só assim os professores poderão assumir atitudes conscientes, deixando de experimentar todas as receitas que Ihes são sugeridas, transformando-se de professores intuitivos em também reflexivos, capazes de investigar sobre suas práticas e selecionar aquelas que são favoráveis ao aprendizado de uma língua estrangeira, especialmente a do português do Brasil como segunda língua.

\section{BIBLIOGRAFIA}

ALMEIDA FILHO, J.C.P.: Dimensões Comunicativas no Ensino de Línguas. Campinas: Pontes Editores, 1993.

ALMEIDA FILHO, J.C.P.:Tendências na Formação Continuada do Professor de Língua Estrangeira. Mimeo. Campinas: Unicamp,1995.

CAVALCANTI, M.C. e MOITA LOPES, L. P. da: Implementação de Pesquisa na Sala deAula de Línguas no Contexto Brasileiro. In Trabalhos de Lingüística Aplicada, Campinas (17). Jan/jun, 1991, pp 133-144.

COLLINS, Allan; GENTNER, Dedre. How people construct mental models. In; QUINN,Naomi; HOLLAND, Doroty. Cultural Models In Language and Thought. Cambridge: Cambridge University Press, 1987.

D'ANDRADE, Roy. A folk model of the mind. In QUINN,Naomi; HOLLAND, Dorothy. Cultural Models in Language and Thought. Cambridge: Cambridge University Press, 1987.

GIMENEZ, Telma N. : Learners becoming Teachers. Dissertação de Doutorado. Lancaster University, 1994.

KRAMSCH, Claire. The cultural component of language teaching. URL: www.spz.tu- 
darmstadt.de/projekt ejournal/jg 01 2/beitrag/kramsch2.htm> Acesso em 26 maio de2003.

KRASHEN, S. Principles and Practice in Second Language Acquisition. Oxford: Pergamon Press, 1982.

MOITA LOPES, L. P. da: Interação e Aprendizagem de Leitura em Sala de Aula de Língua Estrangeira e Materna na Escola Pública.In Moita

Lopes,L.P.\&Molicca, M.C.(org.):Espaços e Interfaces da Língüística e da Lingüística Aplicada. Cadernos Pedagógicos, n. 17.Rio de Janeiro: UFRJ, 1995.

MOITA LOPES, L. P. da: Linguagem/Interação e Formação do(a)

Professor(a).Programa de Lingüística Aplicada da Universidade Federal do Rio de Janeiro, 1996.

MOURA, Patrícia Mayra. A organização conceitual em adultos pouco escolarizados. In Oliveira Marcos e Oliveira Marta (orgs). Investigações Cognitivas. Porto Alegre. Artes médicas.1999

NUNAN, David. Research methods in language learning. New York: Cambridge University Press, 1992.

REYNALDI, Maria Ângela Abbade Chimelo. A cultura de ensinar língua materna e língua estrangeira em um contexto brasileiro. São Paulo. USP.1999. Dissertação de mestrado.

WIDDOWSON, Henry G. O ensino de línguas para a comunicação. Campinas: Pontes, 1991. 